\title{
FGF-23: state of the art
}

\section{Authors}

Rodrigo Bueno de Oliveira ${ }^{1}$

Rosa Maria Affonso Moysés ${ }^{2}$

'Discipline of Nephrology of the Universidade Santo Amaro, Discipline of Nephrology - Hospital das Clínicas of the Faculdade de Medicina da Universidade de São Paulo - HCFMUSP

${ }^{2}$ Kidney Physiopathology Medical Research

Laboratory - LIM16, Discipline of Nephrology - HCFMUSP

Submitted on: 07/10/2010 Accepted on: 07/11/2010

Corresponding author: Rodrigo Bueno de Oliveira R. Santo Aristides, 182, ap 2. Santo Amaro - São Paulo São Paulo

CEP: 04747-110

E-mail: buenomed@gmail. com

This study was conducted at the Hospital das Clínicas of the Faculdade de Medicina da Universidade de São Paulo - HCFMUSP.

We declare no conflict of interest.

\section{Abstract}

Approximately 10 years ago, a member of the family of the fibroblast growth factors, the hormone FGF-23 (fibroblast growth factor 23) was discovered. Its currently known functions involve phosphorus $(\mathrm{P})$ metabolism and inhibition of $1 \alpha$ hydroxylase, the enzyme responsible for the synthesis of calcitriol. That discovery led to a better understanding of the mechanisms of $P$ control, an element associated with mortality, especially in chronic kidney disease. This study reviews several aspects of that hormone, such as its discovery, function, production, mechanism of action, and the most recent clinical studies about it. Afterwards, a discussion about the possible effects of those studies on clinical practice will be presented.

Keywords: chronic kidney failure; phosphorus; parathyroid hormone; fibroblast growth factor receptors.

[J Bras Nefrol 2010;32(3):316-323] @Elsevier Editora Ltda.

\section{INTRODUCTION}

Approximately 10 years ago, ${ }^{1}$ a member of the family of the fibroblast growth factors, the hormone FGF-23 (fibroblast growth factor 23) was discovered. Its currently known functions involve the phosphorus $(\mathrm{P})$ metabolism and inhibition of $1 \alpha$ hydroxylase, the enzyme responsible for the synthesis of calcitriol. ${ }^{2}$ That discovery led to a better understanding of the mechanisms of $\mathrm{P}$ control, an ion associated with mortality, especially in chronic kidney disease $(\mathrm{CKD})$.
In the past two decades, the role of $\mathrm{P}$ in the body has been emphasized and innumerous studies have shown the association between $\mathrm{P}$ and mortality, ${ }^{3-9}$ suggesting that $P$ could be a toxic element in certain circumstances. However, for many years, P has been believed not to be a deleterious factor in patients with CKD, because it remains within the reference range for a long period in the course of that disease. ${ }^{10}$ One possible explanation for the phenomenon of $\mathrm{P}$ increase observed in late stages of CKD was the trade off theory, ${ }^{11,12}$ according to which loss of kidney function could lead to P retention, followed by hypocalcemia, and consequent elevation in serum PTH. However, those against that theory stated that PTH elevation preceded hyperphosphatemia, and, thus, that phenomenon could not be triggered by hyperphosphatemia.

The discovery of FGF-23 has contributed to better understand that theory. Replacing the above-cited term "hyperphosphatemia" by "P overload", it would be possible that, through the action of PTH and FGF-23, P excretion could be increased and its serum levels would be maintained within the reference range for long periods in the course of CKD. The consequence of that adaptation would be an elevation in PTH and FGF-23, in addition to a reduction in calcitriol levels.

Based on that concept, several clinical implications can be speculated and related to CKD mineral and bone disorder (CKDMBD). The following sections provide a review of several aspects of that hormone, such as its discovery, function, production, mechanism of action, and the most recent clinical studies about it. Afterwards, a discussion about the effects of those studies on clinical practice is presented. 


\section{Discovery of FGF-23}

The first reports on phosphatonins date back to $1994,,^{13,14}$ in studies of patients with tumor-induced osteomalacia. Cultures of tumor cells revealed the presence of a 10 to $30 \mathrm{kDa}$ thermosensitive factor that inhibited the $\mathrm{Na}$-dependent tubular transportation of $\mathrm{P}$, but not that of other substances, such as glucose and amino acids. That thermosensitive factor was named phosphatonin. The result of that phenomenon was the biochemical phenotype of hypophosphatemia, increased $\mathrm{P}$ renal excretion, and low calcitriol $\left(1 \alpha, 25(\mathrm{OH})_{2} \mathrm{D}_{3}\right)$ concentrations, consistent with the alterations observed in patients with autosomal dominant hypophosphatemic rickets and tumor-induced osteomalacia.

After six years, that phosphatonin was identified as a member of the fibroblast growth factor (FGF) family. ${ }^{1}$ The first member of that family, FGF-1, was identified in $1989^{15}$, isolated from fibroblasts of the brain and pituitary gland. By the year 2000, 22 members of that family had been identified and their functions included: angiogenesis, mitogenesis, cell differentiation, tissue repair, and metabolic regulation. ${ }^{16,17}$

In $2000^{1}$, Japanese researchers identified, through homology assessment between the fibroblast growth factor 15 (FGF-15) of a mouse embryo and the use of a genetic database (GenBank Nucleotide Sequence Database), a new factor in the fibroblast growth factor family, named FGF-23. ${ }^{1}$ In addition, through homology assessment between the amino acid sequence of FGF-23 of mouse and human DNA, human FGF23 could be located. On that occasion, the FGF-23 of mouse proved to be expressed mainly in the ventrolateral thalamic nucleus of the brain. The FGF-23 functions were not known, but FGF-23 was believed to play an important role in the functions of the ventrolateral thalamic nucleus. ${ }^{1}$

In that same year, a group of researchers reported that patients with autosomal dominant hypophosphatemic rickets had a mutation in the gene that produced the FGF- 23, and that mutation might be the cause of hypophosphatemia, increased $\mathrm{P}$ renal excretion, and low $1 \alpha, 25(\mathrm{OH})_{2} \mathrm{D}_{3}$ concentrations. ${ }^{18}$

In the following year, the DNA sequences abundantly expressed in patients with tumor-induced osteomalacia were cloned. Those sequences were compared with sequences available in a genetic database (GenBank Nucleotide Sequence Database). A long and very frequent DNA sequence encoded a protein with 251 amino acids and molecular weight of 28 $\mathrm{kDa}$, which had the same homology of the fibroblast growth factor family, with an $\mathrm{N}$-terminal region and another C-terminal region, identical to FGF-23.,19 Thus, FGF-23 was characterized as the causal factor of tumor-induced osteomalacia. ${ }^{19}$

\section{Functions of FGF-23}

One of the first in vivo demonstrations of the FGF23 actions occurred in mice receiving that hormone intraperitoneally. The animals had a reduction in serum $\mathrm{P}$ and an increase in $\mathrm{P}$ renal excretion, with no alteration in urine excretion of amino acids and Ca. ${ }^{19}$ Therefore, FGF-23 seemed to act specifically on $\mathrm{P}$ metabolism. Additional evidence revealed that mice receiving implantation of FGF-23-producing tumor cells, derived from the ovary of Chinese hamsters, had growth delay, hypophosphatemia, increased $P$ renal excretion, and a reduction in $1 \alpha, 25(\mathrm{OH})_{2} \mathrm{D}_{3}$ concentrations with a reduction in the expression of $1 \alpha$ hydroxylase. ${ }^{19}$

In $2002^{20}$, the same group of researchers showed that the mutation of the FGF-23 gene resulted in the modification of the proconvertase (176 RHTR 179) site in the $\mathrm{COOH}$-terminal region of the encoded peptide. Replacement of the arginine residues at either position 176 or 179 eliminated the cleavage site. The uncleaved mutant form of FGF-23 had a longer half-life. Its persistence in the circulation resulted in hypophosphatemia, increased $\mathrm{P}$ renal excretion, and low $1 \alpha, 25(\mathrm{OH})_{2} \mathrm{D}$ concentrations.

The increase in $\mathrm{P}$ renal excretion caused by FGF23 was related to the inhibition of $\mathrm{Na}$-dependent $\mathrm{P}$ reabsorption (Na-P cotransporters IIa and IIc) $)^{21,22}$, through the activated protein kinase pathway. ${ }^{23}$

The physiological role of FGF-23 in the metabolism of $\mathrm{P}$ and $1 \alpha, 25(\mathrm{OH})_{2} \mathrm{D}_{3}$ was clarified when studying mice with ablation of the FGF-23 gene. Those animals had growth delay, died between the 10th and 14th weeks of life, and had high serum $P$ levels. ${ }^{24}$ In contrast, transgenic mice with increased FGF-23 expression had decreased serum P, increased urinary excretion of $\mathrm{P}$ and reduced levels of $\mathrm{Na}-\mathrm{P}$ cotransporters. $^{25,26}$

Later studies have assessed the role of P overlo$\mathrm{ad}$ in the regulation of FGF-23 levels. In vitro studies with osteoblast-like cells have shown that P overload stimulated the FGF-23 synthesis by those cells. ${ }^{27} \mathrm{~A}$ study with healthy young males has shown that serum FGF-23 levels are regulated not only by the serum $\mathrm{P}$ level, but also by the $\mathrm{P}$ load originating from the diet. ${ }^{28}$ In that study, after five days of a P-rich diet, changes in FGF-23 levels were observed to positively 
correlate with renal excretion of $\mathrm{P}$, and negatively with $1 \alpha, 25(\mathrm{OH})_{2} \mathrm{D}_{3}$ levels. The serum P level did not change, probably due to the phosphaturic effect of FGF-23.

Based on those results, FGF-23 was concluded to have a function distinct from that of other members of the FGF family, acting mainly as a phosphaturic factor. Unlike PTH, FGF-23 not only increases P renal excretion but also reduces $1 \alpha, 25(\mathrm{OH})_{2} \mathrm{D}_{3}$ synthesis, leading to a negative $\mathrm{P}$ balance. ${ }^{29}$

\section{Production and mechanisms of action of FGF-23}

Several tissues express FGF-23, such as bone tissue, bone marrow vessels, ventrolateral thalamic nucleus, thymus, and lymph nodes..$^{30}$ The relative contribution of those tissues to FGF-23 expression is unknown, but the high levels of expression by osteocytes suggest that the bone tissue is the major source of FGF-23. ${ }^{2}$

For FGF-23 to exert its phosphaturic effect and reduce $1 \alpha, 25(\mathrm{OH})_{2} \mathrm{D}_{3}$ levels, it has to bind to one of the four receptors of the FGF receptor (FGFR) family. ${ }^{2}$ Heparin sulfate proteoglycans and Klotho protein act on that binding as cofactors. Klotho protein is a type I membrane protein containing 1014 amino acids and is mainly expressed in the renal proximal tubules, parathyroid gland, and choroid plexus of the brain. ${ }^{31}$

After Klotho protein binds to FGFR, a conversion of those receptors occurs to increase their binding affinity with FGF-23, rather than with other members of the FGF family. Therefore, the interaction between Klotho and FGFR (FGFR 1c, 3c, 4c) causes a renotropic action of FGF-23 with those receptors, mainly expressed in the renal tissue. The FGF-23/Klotho/FGFR complex leads to phosphorylation of the extracellular signal-regulated protein kinase (ERK) and activation of the early growth response factor 1 (Egr-1). ${ }^{32}$ Those phenomena reduce the expression of $\mathrm{Na}-\mathrm{P}$ cotransporters, triggering phosphaturia. The action of FGF-23 is not blocked by PTH receptor antagonists, suggesting that it acts independently from cyclic AMP. ${ }^{13,14,33,34}$

Inactivation of the Klotho protein relates to several aging phenomena, such as thymus atrophy, sterility, pulmonary emphysema, ataxia, skin atrophy, muscle loss, and osteopenia. ${ }^{35}$ Recent data have also indicated a relation between Klotho protein and mineral metabolism, vitamin $\mathrm{D}$, insulin/glucose, oxidative stress, and vascular calcifications. ${ }^{36}$ Klotho protein is known to inhibit the insulin/insulin-like growth factor (I/IGF1) signaling ${ }^{37}$ and increases resistance to oxidative stress by increasing superoxide dismutase, an enzyme that favors the removal of oxygen reactive species. ${ }^{38}$
In the past decade, several studies have shown that FGF-23, more specifically the Klotho-FGF-23 axis, is deeply involved in the regulatory systems of $\mathrm{P}$ metabolism, playing a central role in its regulation. In parallel with that major system, other phosphatonins have been described, such as FGF-7, secreted frizzled related protein-4 (sFRP-4), and matrix extracellular phosphoglycoprotein (MEPE), whose functions have not yet been fully elucidated. ${ }^{29}$

\section{FGF-23 AND CLINICAL AND EXPERIMENTAL STUDIES}

The mechanism of action of FGF-23 on the P metabolism in CKD has been a matter of speculation for some time. Thus, the hypothesis that the synthesis of FGF-23 would be induced by $\mathrm{P}$ retention is very attractive. ${ }^{39}$

Several studies have shown the correlation between the serum levels of FGF-23 and creatinine, P and PTH in patients with nondialysis CKD. ${ }^{40-43}$ The levels of that hormone increases as renal function decreases. ${ }^{41}$ Even in patients with a glomerular filtration rate higher than $80 \mathrm{~mL} / \mathrm{min}, \mathrm{FGF}-23$ levels correlate negatively with $1 \alpha, 25(\mathrm{OH})_{2} \mathrm{D}_{3}$ and $\mathrm{P}$ tubular reabsorption.

A study with 80 patients with nondialysis CKD has shown that FGF-23 and PTH were inversely correlated with glomerular filtration rate, and FGF-23 levels showed an early increase, independently of $\mathrm{P}$ levels, $\mathrm{P}$ excretion fraction, and $1 \alpha, 25(\mathrm{OH})_{2} \mathrm{D}_{3}$ deficiency. In addition, FGF-23 was a strong predictor of the reduction in $1 \alpha, 25(\mathrm{OH})_{2} \mathrm{D}_{3}$ levels. The authors have concluded that the increase in FGF-23 can contribute to maintain $P$ levels within the reference range even in advanced phase of CKD, but can worsen the $1 \alpha, 25(\mathrm{OH})_{2} \mathrm{D}_{3}$ deficiency, a phenomenon that can be the central event in the pathogenesis of secondary hyperparathyroidism. Another interesting result is that hyperphosphatemia occurred only in $12 \%$ of the patients, all of whom had glomerular filtration rate lower than $30 \mathrm{~mL} / \mathrm{min}^{.44}$

Clinical studies have shown an association of high FGF-23 levels and CKD progression, ${ }^{45,46}$ development of severe secondary hyperparathyroidism, ${ }^{47}$ left ventricle hypertrophy, ${ }^{48}$ and mortality. ${ }^{49}$

A recent study with 177 nondiabetic patients with serum creatinine ranging from 0.9 to $4.9 \mathrm{mg} / \mathrm{dL}$, followed up for a mean period of 53 months, has reported that FGF-23 was a predictor of the progression of renal disease as important as glomerular filtration rate. ${ }^{45}$ In another study with 55 patients with stage III diabetic nephropathy with macroalbuminuria 
followed up for a mean period of 30.7 months, the FGF-23 level was also an isolated predictive factor for the evolution of diabetic nephropathy, regardless of the levels of $\mathrm{P}, \mathrm{Ca}, \mathrm{PTH}$, and $25(\mathrm{OH})_{2} \mathrm{D}_{3}{ }^{46}$

The hypothesis that high FGF-23 levels are associated with secondary hyperparathyroidism has been demonstrated in a study with 103 patients undergoing hemodialysis. By the end of two years, patients who had high FGF-23 levels at the beginning of the study developed more severe forms of secondary hyperparathyroidism, independently of the initial PTH levels. ${ }^{47}$

Gutierrez et al. have shown that FGF-23 levels were independently associated with the left ventricular mass index and left ventricular hypertrophy in a group of 162 patients with nondialysis CKD. ${ }^{48}$ However, further studies seem to be required to clarify if the increase in FGF-23 is only a marker of ventricular hypertrophy or is deleterious to cardiac tissue.

A prospective cohort of 10,044 incident patients undergoing hemodialysis has shown that the increase in the FGF-23 levels at the beginning of dialysis associated with a higher mortality rate, independently of the serum P levels and of other known risk factors. The magnitude of the mortality risk associated with FGF-23 was greater when compared with the risk attributed to serum P levels. ${ }^{49}$

In addition to the possible relations between FGF-23, CKD progression, hyperparathyroidism, ventricular hypertrophy, and mortality, high FGF-23 levels are believed to correlate with vascular calcification. ${ }^{50,51}$ Our group studied, for one year, $72 \mathrm{pa}$ tients undergoing hemodialysis and found a positive correlation between FGF-23 levels and the vascular calcification score assessed by use of coronary tomography in the group of patients treated with sevelamer hydrochloride. ${ }^{52}$

\section{Discussion}

An important question that remains unanswered relates to the possible existence of other actions of FGF23 , whether that hormone is only an indirect marker of toxicity of other factors, like $\mathrm{P}$, or whether it has a direct toxic effect on vascular endothelium and renal tissue. Persistently elevated levels of FGF-23 may favor a high-affinity binding to the FGF receptor, independently of the Klotho cofactor, stimulating the production of factors involved in the development of vascular disease. The increase in FGF-23 levels may reflect only the prolonged exposure to P-rich diets. In addition to excessive FGF-23 levels, its combination with $1,25(\mathrm{OH})_{2} \mathrm{D}_{3}$ deficiency would have a greater adverse effect, being associated with higher mortality of human beings. ${ }^{49}$

Returning to the trade off theory, replacing the term "hyperphosphatemia" by "P retention" would make that theory more plausible from the biological viewpoint. The evolution of the biological processes related to $\mathrm{P}$ metabolism seems to have created two systems to prevent $\mathrm{P}$ accumulation, the FGF-23/ Klotho axis and the PTH axis, being the latter clearly demonstrated by the trade off theory. Thus, in the course of CKD, P levels would be maintained within the reference range for long periods because of PTH and FGF-23 actions. The trigger of the two systems to prevent $\mathrm{P}$ retention would be $\mathrm{P}$ load itself.

Another interesting point is the possibility of FGF-23 being a marker of CKD-MBD. To date, the best marker of the mineral and bone metabolism for analyzing clinical outcomes, such as CKD progression and mortality, remains unknown. Most probably PTH, vitamin D, Klotho, and FGF-23 are distinct markers of $\mathrm{P}$ overload, and can be used as markers of the bone and mineral metabolism.

In the case of FGF-23, a special characteristic could favor its use as a marker of CKD-MBD: the fact that FGF-23 concentrations remain stable throughout the day in patients with CKD, ${ }^{33,54}$ contrary to that which happens with $\mathrm{PTH}$, which varies in the post-prandial period ${ }^{53}$ and is influenced by the serum levels of $25(\mathrm{OH})_{2} \mathrm{D}_{3}{ }^{55}$

Another unanswered question is whether FGF23 levels could be modulated by P binders, such as calcium acetate or sevelamer hydrochloride. In the case that therapeutic strategy proves to be feasible, probably it could benefit patients with CKD, mainly at earlier stages.

So far, only five studies, one in animals and four in humans, have shown the effects of P binders on serum FGF-23 levels. The first study has shown a reduction in the levels of FGF-23, P, and PTH with the use of sevelamer hydrochloride in animals with CKD. That reduction was reversed with drug suspension. ${ }^{56}$

Another study involving six dialysis patients has shown that the suspension of $\mathrm{P}$ binders increased FGF-23 levels, although not significantly. ${ }^{57}$ Our group has studied prospectively the effects of $\mathrm{P}$ binders, calcium acetate and sevelamer hydrochloride, in hemodialysis patients and has observed a significant reduction in FGF-23 levels after one year of treatment, and patients treated with sevelamer hydrochloride had a more significant reduction than those treated with calcium acetate. ${ }^{52}$ 
Another study assessed the effects of calcium carbonate in association with sevelamer hydrochloride as compared with the isolate use of calcium carbonate in 46 hemodialysis patients followed up for four weeks. The results have shown a reduction in $\mathrm{P}$ and FGF-23 only in patients treated with the association of drugs. ${ }^{58}$

Our group has studied 42 normophosphatemic patients with CKD stages III and IV undergoing conservative treatment for CKD. The patients were randomized into two groups to receive progressive doses of calcium acetate or sevelamer hydrochloride for six weeks. At the beginning of the study, most patients had an elevation in serum PTH and FGF-23 levels, and normal $\mathrm{P}$ and calcium levels. After six weeks of treatment, a reduction in serum PTH levels and in P excretion fraction was observed, with alteration neither in P nor in calcium levels. Only in the sevelamer group, a reduction in serum FGF-23 levels was observed. ${ }^{59}$ That result has important clinical implications. Similarly to the trade off theory ${ }^{13,14}$ proposed to PTH, mild elevations in FGF-23 could prevent hyperphosphatemia in the early stages of CKD. However, in the long run, excessive FGF-23 could favor negative clinical outcomes, such as the development of secondary hyperparathyroidism, rapid progression to CKD, and a higher mortality rate. ${ }^{45-50}$ Thus, modulating serum FGF-23 levels can benefit patients, reducing adverse events, especially those related to disorders of the bone and mineral metabolism.

Considering the possibility of $\mathrm{P}$ binders modulating serum FGF-23 levels, we would be facing a new perspective regarding the early use of $P$ binders in normophosphatemic CKD patients. The current recommendation is $\mathrm{P}$ dietary restriction only for hyperphosphatemic patients. However, when considering that the elevation in P levels occurs only in the late phases of CKD, and that the trigger for the elevation in PTH and FGF-23 levels is P overload, emphasis should not be given to phosphatemia but rather to $\mathrm{P}$ overload, expressed through the elevation in FGF-23 levels.

That approach directed towards the reduction in $\mathrm{P}$ overload could contribute to the early control of PTH levels. Such control exerted since the early stages of CKD is probably beneficial to patients, because some studies have shown an association between high PTH levels and bone disease, in addition to cardiovascular disease, one of the major causes of death in that population. A study with healthy individuals has shown that the continuous infusion of 1-34 PTH for 12 days was associated with an increase in blood pressure. ${ }^{60}$
Another study with 1,784 individuals followed up for seven years has revealed that PTH levels predicted systolic hypertension in men, even after correcting for factors such as age, body mass index, and tobacco use. ${ }^{61} \mathrm{~A}$ study with 2,040 individuals assessing the relation between PTH and left ventricular hypertrophy has found that, in men over the age of 59 years and women under 60 years, PTH was a significant predictor of left ventricular hypertrophy. ${ }^{62}$ In a study with 958 individuals (mean age of 71 years), 617 of whom with no previous cardiovascular disease, the serum PTH level was a predictor of cardiovascular mortality, even in those with PTH values within the reference range. ${ }^{6}$ In addition to those effects on the cardiovascular system, PTH contributes to the development of vascular calcification. An experimental study has shown that vascular endothelial cells, when stimulated with PTH, showed a reduction in the expression of the messenger RNA of osteoprotegerin, a known protection factor of vascular endothelium. ${ }^{63}$

The mechanism involved in reducing FGF-23 levels by using $\mathrm{P}$ binders, specifically sevelamer, is unknown. ${ }^{59}$ Sevelamer is believed to decrease oxidative stress and inflammatory markers because of its pleiotropic effects on the vascular endothelium of patients with CKD. ${ }^{64,65}$ That effect could result from the sevelamer's property of chelating endotoxins in the intestine, thus preventing intestinal uptake of substances that stimulate inflammatory response. ${ }^{64} \mathrm{~A}$ study with 31 hemodialysis patients has reported a reduction in the parameters of oxidative stress and inflammatory markers in patients treated with sevelamer for one year when compared with a group of patients receiving calcium acetate ${ }^{65} \mathrm{~A}$ similar finding has been observed in another study with 23 hemodialysis patients. After replacing calcium carbonate with sevelamer, those patients were followed up for six months and the levels of PCR and endotoxins significantly decreased as follows: PCR dropped from $4.8 \pm 1.2 \mathrm{mg} / \mathrm{L}$ to $0.44 \pm 0.12 \mathrm{mg} / \mathrm{L}$; and endotoxins, from $3.6 \pm 0.8 \mathrm{mg} / \mathrm{L}$ to $1.2 \pm 0.6 \mathrm{EU} / \mathrm{mL} .{ }^{66}$

Another unanswered question is the role of $\mathrm{Ca}$ in FGF-23 regulation, in addition to the other two known regulators of that hormone ( $\mathrm{P}$ and calcitriol). A study conducted with patients with primary hyperparathyroidism and undergoing parathyroidectomy has revealed that serum FGF-23 levels correlated with serum Ca levels, regardless of serum P. ${ }^{67}$ Another study with mice without vitamin $\mathrm{D}$ receptors has shown that calcium can be another determinant for the production of FGF-23. In those animals, FGF-23 levels were almost undetectable. The intravenous administration 
of recombinant FGF-23 reduced serum P levels through independent mechanisms of the calcitriol/vitamin $\mathrm{D}$ receptor pathway. When those animals received a Ca-supplemented diet, a significant increase was observed in the expression of the messenger RNA of FGF-23 in bone tissue, thus indicating that Ca could be another determinant of FGF-23 production. ${ }^{68}$ Recently, our group has studied 72 hemodialysis patients, in whom bone remodeling and the effects of $\mathrm{Ca}$ overload were assessed. At the beginning of the study, after a period without P binders and calcitriol, patients underwent bone biopsy, computed tomography of the coronary arteries for assessing Ca score, in addition to measuring biochemical markers of bone remodeling. The patients were then randomized into two groups, treated with calcium acetate or sevelamer hydrochloride. After one year, they underwent a new bone biopsy and computed tomography of the coronary arteries. During follow-up, calcitriol prescription and $\mathrm{Ca}$ concentration in dialysis bath were adjusted according to the $\mathrm{Ca}, \mathrm{P}$, and $\mathrm{PTH}$ levels and to the type of bone remodeling detected on bone biopsy at the beginning of the study. The results revealed that patients treated with calcitriol, or calcium acetate, and whose bath contained more $\mathrm{Ca}\left(\mathrm{Ca}^{++}=\right.$ $3.5 \mathrm{mEq} / \mathrm{L}$ ) had higher FGF-23 levels by the end of the first year. ${ }^{52}$ Knowing that $\mathrm{Ca}$ overload influences FGF-23 levels can have implications with important clinical outcomes, such as mortality and cardiovascular disease, since several studies have shown the association between high FGF-23 levels and those clinical outcomes. ${ }^{45-50}$

Considering all those unanswered questions, a recent review on the topic draws attention to the importance of better understanding the role played by $\mathrm{P}$ and FGF-23 in CKD, proposing to the nephrological community a randomized, controlled, long-term study using $\mathrm{P}$ binders in the early phases of CKD, and analyzing clinical outcomes, such as vascular calcification, bone health, and CKD progression. ${ }^{69}$

\section{Conclusions}

Several studies have consolidated the role of $\mathrm{P}$ as a potentially toxic element, associated with increased mortality rate. The discovery of FGF-23 led to a better understanding of $\mathrm{P}$ metabolism and its several clinical CKD-MBD-related implications.

Further studies are necessary to define the usefulness of FGF-23 as a marker in CKD-MBD, or even as a therapeutic target. The effect of the use of $\mathrm{P}$ binders on FGF-23 levels and its clinical repercussion in outcomes as mortality and CKD progression need to be clarified in future controlled and randomized studies with a significant number of participants.

\section{References}

1. Yamashita T, Yoshioka M, Itoh N. Identification of a novel fibroblast growth factor, FGF-23, preferentially expressed in the ventro-lateral thalamic nucleus of the brain. Biochem Biophy Res Comm 2000; 277:494-8.

2. Liu S, Quarles LD. How fibroblast growth factor 23 works. J Am Soc Nephrol 2007; 18:1637-47.

3. Block GA, Cunningham J. Morbidity and mortality associated with abnormalities in bone and mineral metabolism in CKD. In: Olgard K (ed). Clinical guidelines to the basics of bone and mineral metabolism in CKD. Chapter 4, National kidney foundation: New York, 2006, pp. 77-92.

4. Block GA, Klassen PS, Lazarus JM, Ofsthun N, Lowrie EG, Chertow GM. Mineral metabolism, mortality, and morbidity in maintenance hemodialysis. J Am Soc Nephrol 2004; 15:2208-18.

5. Kestenbaum B, Sampson JN, Rudser KD et al. Serum phosphate levels and mortality risk among people with chronic kidney disease. J Am Soc Nephrol 2005; 16:520-8.

6. Hagstrom E, Hellman P, Larsson TE et al. Plasma parathyroid hormone and the risk of cardiovascular mortality in the community. Circulation 2009; 119:2765-71.

7. Foley RN. Phosphate levels and cardiovascular disease in the general population. Clin J Am Soc Nephrol 2009; 4:1136-9.

8. Dhingra R, Sullivan LM, Fox CS et al. Relations of serum phosphorus and calcium levels to the incidence of cardiovascular disease in the community. Arch Intern Med 2007; 167:879-85.

9. Tonelli M, Sacks F, Pfeffer M, Gao Z, Curhan G. Relation between serum phosphate level and cardiovascular event rate in people with coronary disease. Circulation 2005; 112:2627-33.

10. Levin A, Bakris GL, Molitch M et al. Prevalence of abnormal serum vitamin D, PTH, calcium, and phosphorus in patients with chronic kidney disease: results of the study to evaluate early kidney disease. Kidney Int 2007; 71:31-8.

11. Slatopolsky E, Gradwska A, Kashemsant C, Keltner R, Manley C, Bricker NS. The control of phosphate excretion in uremia. J Clin Invest 1966; 45:672-7.

12. Slatopolsky E, Caglar S, Pennell JP et al. On the pathogenesis of hyperparathyroidism in chronic experimental renal insufficiency in the dog. J Clin Invest 1971; 50: 492-9.

13. Cai Q, Hodgson SF, Kao PC et al. Brief report: inhibition of renal phosphate transport by a tumor product in a patient with oncogenic osteomalacia. N Engl J Med 1994; 330:1645-9.

14. Econs MJ, Drezner MK. Tumor-induced osteomalacia - unveiling a new hormone. New Engl J Med 1994; 330:1679-81.

15. Burgess WH, Maciag T. The heparin-binding (fibroblast) growth factor family of proteins. Annu Rev Biochem 1989; 58:575-606. 
16. Mckeehan WL, Wang F, Kan M. The heparan sulfatefibroblast growth factor family: diversity of structure and function. Prog Nucleic Acid Res Mol Biol 1998; 59:135-76.

17. Martin GR. The roles of FGFs in the early development of vertebrate limbs. Genes Dev 1998; 12:1571-86.

18. ADHR Consortium. Autossomal dominant hypophosphataemic rickets is associated with mutations in FGF23. Nat Genet 2000; 26:345-8.

19. Shimada T, Mizutani S, Muto $T$ et al. Cloning and characterization of FGF-23 as a causative factor of tumor-induced osteomalacia. Proc Natl Acad Sci 2001; 98:6500-5.

20. Shimada T, Muto T, Urakawa I et al. Mutant FGF-23 responsible for autosomal dominant hypophosphatemic rickets is resistant to proteolytic cleavage and causes hypophosphatemia in vivo. Endocrinology 2002; 143:3179-82.

21. Bowe AE, Finnegan R, Jan de Beur SM et al. FGF23 inhibits renal tubular phosphate transport and is a PHEX substrate. Biochem Biophys Res Commun 2001; 284:977-81.

22. Murer H, Hernando N, Foster I, Biber J. Regulation of $\mathrm{Na} / \mathrm{Pi}$ transporter in the proximal tubule. Annu Rev Physiol 2003; 65:531-42.

23. Yamashita T, Konishi M, Miyake A, Inui K, Itoh N. Fibroblast growth factor (FGF)-23 inhibits renal phosphate reabsorption by activation of the mitogen-activated protein kinase pathway. J Biol Chem 2002; 277:28265-70

24. Shimada T, Kakitani M, Yamazaki Y et al. Targeted ablation of FGF-23 demonstrates an essential physiological role of FGF-23 in phosphate and vitamin D metabolism. J Clin Invest 2004; 113:561-8.

25. Larsson T, Marsell R, Schipani E et al. Transgenic mice expressing fibroblast growth factor 23 under the control of the $\square 1$ (I) collagen promoter exhibit growth retardation, osteomalacia, and disturbed phosphate homeostasis. Endocrinology 2004; 145:3087-94.

26. Shimada T, Urakawa I, Yamazaki Y et al. FGF-23 transgenic mice demonstrate hypophosphatemic rickets with reduced expression of sodium phosphate cotransporter type IIa. Biochem Biophys Res Commun 2004; 314:409-14.

27. Mirams M, Robinson BG, Mason RS, Nelson AE. Bone as a source of FGF-23: regulation by phosphate? Bone 2004; 35:1192-9.

28. Ferrari SL, Bonjour JP, Rizzoli R. Fibroblast growth factor 23 relationship to dietary phosphate and renal phosphate handling in healthy young men. J Clin Endocrinol Metab 2005; 90:1519-24.

29. Berndt T, Schiavi S, Kumar R. "Phosphatonins" and the regulation of phosphorus homeostasis. Am J Renal Physiol 2005; 289:F1170-82.

30. Liu S, Guo R, Simpson LG, Xiao ZS, Burnham CE, Quarles LD. Regulation of fibroblast growth factor 23 expression but not degradation by PHEX. J Biol Chem 2003; 278:37419-26.

31. Matsumara Y, Aizawa H, Shiraki-Iida T, Nagai R, Kuro-o M, Nabeshima Y. Identification of the human Klotho gene and its two transcripts encoding membrane and secreted Klotho protein. Biochem and Biophys Res Commun 1998; 242:626-30.
32. Urakawa I, Yamazaki Y, Shimada T et al. Klotho converts canonical FGF receptor into a specific receptor for FGF-23. Nature 2006; 444:770-4.

33. Kumar R. Phosphatonin - a new phosphaturetic hormone? (lessons from tumor- induced osteomalacia and X-linked hypophosphataemia). Nephrol Dial transplant 1997; 12:11-13.

34. Kumar R. Tumor-induced osteomalacia and the regulation of phosphate homeostasis. Bone 2000; 27:333-8

35. Kuro-o M, Matsumara Y, Aizawa $\mathrm{H}$ et al. Mutation of the mouse Klotho gene leads to a syndrome resembling ageing. Nature 1997; 390:45-51.

36. Torres PU, Prié D, Molina-Blétry V, Beck L, Silve C, Friedlander G. Klotho: an antiaging protein involved in mineral and vitamin D metabolism. Kidney Int 2007; 71:730-7.

37. Kurosu H, Yamamoto M, Clark JD et al. Supression of aging in mice by the hormone Klotho. Science 2005; 309:1829-33.

38. Yamamoto M, Clark JD, Pastor JV et al. Regulation of oxidative stress by the anti-aging hormone Klotho. J Biol Chem 2005; 280:38029-34.

39. Fukagawa M, Nii-Kono T, Kazama JJ. Role of fibroblast growth factor 23 in health and in chronic kidney disease. Curr Opin Nephrol Hypert 2005; 14:325-9.

40. Weber TJ, Liu S, Indridason OS, Quarles LD. Serum FGF-23 levels in normal and disordered phosphorus homeostasis. J Bone Min Res 2003; 18:1227-34.

41. Larsson $T$, Nisbeth $U$, Ljunggren $O$, Jüppner $H$, Jonsson KB. Circulating concentration of FGF-23 increases as a renal function declines in patients with chronic kidney disease, but does not change in response to variation in phosphate intake in healthy volunteers. Kidney Int 2003; 64:2272-9.

42. Imanishi $Y$, Inaba M, Nakatsuka K et al. FGF-23 in patients with end-stage renal disease on hemodialysis. Kidney Int 2004; 65:1943-6.

43. Shigematsu T, Kazama JJ, Yamashita T et al. Possible involvement of circulating fibroblast growth factor 23 in the development of secondary hyperparathyroidism associated with renal insufficiency. Am J Kidney Dis 2004; 44:250-6.

44. Gutierrez O, Isakova T, Rhee E et al. Fibroblast growth factor 23 mitigates hyperphosphatemia but accentuates calcitriol deficiency in chronic kidney disease. J Am Soc Nephrol 2005; 16:2205-15.

45. Fliser D, Kollerits B, Neyer U et al. Fibroblast growth factor 23 (FGF-23) predicts progression of chronic kidney disease: the Mild to Moderate Kidney Disease (MMKD) Study. J Am Soc Nephrol 2007; 18:2600-8.

46. Titan SM, Zatz R, Jorgetti V, Graciolli FG, dos Reis LM, Moysés RMA. FGF-23 as a predictor of renal outcome in diabetic nephropathy [abstract]. J Am Soc Nephrol 2009; PO1872.

47. Nakanishi S, Kazama JJ, Nii-Kono T et al. Serum fibroblast growth factor-23 levels predict the future refractory hyperparathyroidism in dialysis patients. Kidney Int 2005; 67:1171-8.

48. Gutiérrez OM, Januzzi JL, Isakova T et al. Fibroblast growth factor 23 and left ventricular hypertrophy in chronic kidney disease. Circulation 2009; 119:2545-52. 
49. Gutiérrez OM, Mannstadt M, Isakova $\mathrm{T}$ et al. Fibroblast growth factor 23 and mortality among patients undergoing hemodialysis. N Engl J Med 2008; 359:584-92.

50. Jean G, Terrat JC, Vanel T et al. High levels of serum fibroblast growth factor (FGF)-23 are associated with increased mortality in long hemodialysis patients. Nephrol Dial Transplant 2009; 24:2792-6.

51. Jean G, Bresson E, Terrat JC et al. Peripheral vascular calcification in long-haemodialysis patients: associated factors and survival consequences. Nephrol Dial Transplant 2009; 24:948-55.

52. Cancela ALE, Oliveira RB, Graciolli FG et al. Fibroblast growth factor 23 in hemodialysis patients: effects of phosphate binder, calcitriol and calcium concentration in the dialysate. Nephron Clin Pract [in press].

53. Isakova T, Guitierrez O, Shah A et al. Postprandial mineral metabolism and secondary hyperparathyroidism in early CKD. J Am Soc Nephrol 2008; 19:615-23.

54. Nishida Y, Taketani Y, Yamanaka-Okumura H et al. Acute effect of oral phosphate loading on serum fibroblast growth factor 23 levels in healthy men. Kidney Int 2006; 70:2141-7.

55. Gonzalez EA, Sachdeva A, Oliver DA, Martin KJ. Vitamin D insufficiency and deficiency in chronic kidney disease. A single center observational study. Am J Nephrol 2004; 24:503-10.

56. Nagano N, Miyata S, Abe M et al. Effect of manipulating serum phosphorus with phosphate binder on circulating PTH and FGF12 in renal failure rats. Kidney Int 2006; 69:531-7.

57. Pande S, Ritter CS, Rothstein $M$ et al. FGF-23 and sFRP in chronic kidney disease and post-renal transplantation. Nephron Physiol 2006; 104:23-32.

58. Koiwa F, Kazama J, Tokumoto A et al. Sevelamer hydrocloride and calcium bicarbonate reduce serum fibroblast growth factor 23 levels in dialysis patients. Ther Apher Dial 2005; 9:336-9.

59. Oliveira RB, Cancela ALE, Graciolli FG et al. Early control of PTH and FGF-23 in normophosphatemic CKD patients: a new target in CKD-MBD therapy? Clin J Am Soc Nephrol 2010; 5:286-291.
60. Hulter HN, Melby JC, Peterson JC, Cooke CR. Chronic continuous PTH infusion results in hypertension in normal subjects. J Clin Hypertens 1986; 2:360-70.

61. Jorde R, Svartberg J, Sundsfjord J. Serum parathyroid hormone as a predictor of increase in systolic blood pressure in men. J Hypertens 2005; 23:1639-44.

62. Saleh FN, Schirmer H, Sundsfjord J, Jorde R. Parathyroid hormone and left ventricular hypertrophy. Eur Heart J 2003; 24:2054-60.

63. Rashid G, Plotkin E, Klein O, Green J, Bernheim J, Benchetrit S. Parathyroid hormone decreases endothelial osteoprotegerin secretion: role of protein kinase A and C. Am J Physiol Renal Physiol 2009; 296:F60-6.

64. Peres AT, Dalboni MA, Canziani ME et al. Effect of phosphate binders on oxidative stress and inflammation markers in hemodialysis patients. Hemodial Int 2009; 13:271-7.

65. Sun PP, Perianayagam MC, Jaber BL. Endotoxinbinding affinity of sevelamer: a potential novel anti-inflammatory mechanism. Kidney Int 2009; 76:S20-5.

66. Stinghen AEM, Gonçalves SM, Hauser AB, Branco F, Gruber B, Pecoits-Filho R. Sevelamer decreases systemic inflammation in dialysis patients through its endotoxin binding effects [abstract]. In: Renal Week 2009. Am Soc Nephrol 2009; 20:FC384.

67. Kobayashi K, Imanishi Y, Miyauchin A et al. Regulation of plasma fibroblast growth factor 23 by calcium in primary hyperparathyroidism. Eur J Endocrinol 2006; 154:93-9.

68. Shimada T, Yamazaki Y, Takahashi M et al. Vitamin $\mathrm{D}$ receptor independent FGF23 actions in regulating phosphate and vitamin D metabolism. Am J Physiol Renal Physiol 2005; 289:F1088-F1095.

69. Isakova T, Gutiérrez OM, Wolf M. A blueprint for randomized trials targeting phosphorus metabolism in chronic kidney disease. Kidney Int 2009; 76:705-16. 